\section{China boom leaves children behind}

Some 61 million children were left behind by migrant parents in China in 2010-14, or almost $22 \%$ of the country's children (see go.nature.com/clylrn; in Chinese). This side effect of urban development is seriously affecting the mental and physical health of those abandoned juveniles who are uncared for. We urge China's government to weigh this social damage against economic gain and to take steps to mitigate it.

There were 274 million Chinese migrant workers in 2014 - an unprecedented number. Evidence is increasing for the adverse effects of such upheaval on some children's physical, psychological and social development (Q. Li et al. China Econ. Review 36, 367-376 (2015); G. Ding and Y. Bao J. Child Psychol. Psychiatr. 55, 411-412 (2014)).

Despite China's great economic achievements, its childcare services remain underfunded and underdeveloped. There is an urgent need for policy reform and strategies to tackle the problem. These include the development and enforcement of family interventions, community support and schooling improvements. Peng Yuan, Long Wang Xiangya Hospital, Central South University, Changsha, Hunan, China. wanglong@csu.edu.cn

\section{Recover wastewater resources locally}

As contributors to governmental initiatives to reuse wastewater pollutants in the European Union, the United States and China, we consider that decentralized recovery of these resources could result in more environmental, economic and social benefits than the near-term upgrade of centralized facilities (see W.-W. Li et al. Nature 528, 29-31; 2015).

Decentralized local treatment and reuse facilities avoid the large transportation and energy costs of conveying treated wastewater back to catchment areas for reuse. Concentrating nutrients for recovery also consumes large amounts of energy: urine makes up only $1 \%$ of total wastewater volume, and about $80 \%$ of nitrogen and $50 \%$ of phosphate in wastewater are from urine.

However, nitrogen and phosphorus can be locally recovered from urine using urine-diverting toilets, which greatly reduce nutrient loads to existing plants (J. Elser and E. Bennett Nature 478, 29-31; 2011). Similar strategies can be applied to carbon, leading to greater energy recovery through co-digestion of sludge with food waste, and direct carbon capture and storage for climate-change mitigation.

International strategies for nutrients, energy and water ('NEW' initiatives) aim to transform the water infrastructure for resource recovery. By balancing near-term goals and long-term ambitions, water 'waste' should become a misnomer.

Zhiyong Jason Ren University of Colorado, Boulder, USA.

Art K. Umble MWH Global,

Denver, USA.

zhiyong.ren@colorado.edu

\section{Half of samples fail protein-blot tests}

Poorly characterized antibodies give rise to irreproducible results (see, for example, Nature 527, 545-551; 2015), but so can the use of properly validated antibodies in a non-validated context.

At Aviva Systems Biology in California, we used our highly specific commercial antibodies in western immunoblot assays to test more than 1,000 protein samples provided by the research community. We found that the preparation quality of more than half of these samples failed to meet the technical requirements for a reliable assay signal.

Simple technical factors confounded the electrophoretic resolution or antibody detectability of the researchers' protein solutions. These included unsuitable sample concentrations, buffer incompatibility and the absence of calibration markers or treatment controls. Until uniform western-blotting standards are widely adopted (see J. E. Gilda et al. PLoS ONE 10, e0135392; 2015), there is a risk that data irreproducibility will continue to be the norm.

Antibody-production companies should not be treated as casinos for boosting a researcher's chances of a positive result from such shot-in-the-dark samples.

Matt Landry Aviva Systems Biology, San Diego, California, USA.

Aldrin V. Gomes University of California, Davis, USA. mlandry@avivasysbio.com

\section{UK budget cuts erode Paris promises}

Two weeks before the UK government signed up to keep global warming well below $2{ }^{\circ} \mathrm{C}$ at the 2015 United Nations climate summit in Paris, it announced a $22 \%$ budget cut for the Department of Energy and Climate Change. It also scrapped a previously ring-fenced $£ 1$-billion (US\$1.5-billion) budget for developing carbon capture and storage. UK decarbonization targets might be unachievable without this technology.

In our view, these actions signal that the UK government does not treat climate action as a priority, and that it is ignoring the evidence of the research it funds. For example, data collected by the UK Met Office show that 2014 and 2015 have been the warmest years on record.
To regain credibility, the government must overcome internal division (N. Carter and B. Clements Br. Politics 10, 204-225; 2015) and develop a robust climate policy that is in line with its stated ambitions. Alexander C. Lees Cornell University, Ithaca, New York, USA Andrew Balmford, Ben Phalan University of Cambridge, UK. btp22@cam.ac.uk

\section{Come together to study life's origins}

Researchers working on the origins of life tend to fall into two camps - those who investigate artificial life and those who study the origins of life on Earth four billion years ago. The communication gulf between the two needs to be closed if the field is to progress.

Artificial-life researchers are less concerned about how life originated on Earth than with the idea of life as a universal phenomenon - including its emergence and self-organization. And those pursuing experimental verification of mechanisms for terrestrial origins are seldom drawn to the broad theoretical ideas of artificial life.

The Earth-Life Science Institute's Origins Network, working with members of the research community, has issued a statement to encourage fresh approaches to the subject (C. Scharf et al. Astrobiology 15, 1031-1042; 2015). We suggest that origins-of-life research requires inspirational innovation, cross-disciplinary collaboration and reassurance from institutions that such research will be supported. We hope that these proposals will help to train a new generation of scientists to think more broadly and less tribally.

Caleb Scharf Columbia University, New York, USA. Nathaniel Virgo, H. James Cleaves Earth-Life Science Institute, Tokyo, Japan. caleb@astro.columbia.edu 